\title{
Erratum to: Application of the R-matrix method in quantum transport simulations
}

\section{Continuous model}

\section{Gennady Mil'nikov • Nobuya Mori ·} Yoshinari Kamakura

Published online: 12 May 2011

(C) Springer Science+Business Media LLC 2011

\section{Erratum to: J Comput Electron}

DOI 10.1007/s10825-011-0345-Z

The original version of this article was printed without a subtitle. The full title of the article is, "Application of the R-matrix method in quantum transport simulations: Continuous model."

The online version of the original article can be found under doi:10.1007/s10825-011-0345-Z.

G. Mil'nikov $(\bowtie) \cdot$ N. Mori · Y. Kamakura

Graduate School of Engineering, Osaka University,

2-1 Yamada-oka, Suita, Osaka 565-0871, Japan

e-mail: gena@e3.eei.eng.osaka-u.ac.jp

G. Mil'nikov · N. Mori · Y. Kamakura

CREST, JST, 5 Sanbancho, Chiyoda-ku, Tokyo 102-0075, Japan 